\title{
HIGHWAYS DISTURBANCE DETECTION WITH THE USE OF OPEN SOURCE CODE GEOGRAPHIC INFORMATION SYSTEMS, MOBILE AND WEB APPLICATIONS
}

\author{
L. Sabah ${ }^{\mathrm{a}, *}$, M. Şimşek ${ }^{\mathrm{b}}$ \\ a Department of IT, Düzce University, 81620 Düzce, Turkey - leventsabah@ duzce.edu.tr \\ b Department of Computer Engineering, Faculty of Engineering, Düzce University, 81620 Düzce, Turkey - \\ mehmetsimsek@duzce.edu.tr
}

KEY WORDS: Highways Disturbance Detection, Mobile Applications, QGIS, Open Source Geographical Information Systems, Open Source Database Management Systems

\begin{abstract}
:
Road disturbances are occurring in our country due to the highway-weighted transportation. These disturbances are caused by human and natural causes. Disturbances in the roads have a negative effect on human life as well as damage to the vehicles. Regardless of how it occurs, it is important to quickly detect and eliminate roadside disturbances. The use of mobile devices has become widespread with developing technologies. Today, many sensors such as GPS and accelerometer are used to detect road disturbances on mobile devices. In this context, it is important to use mobile applications for fast and in-situ detection. In this study, it is investigated the use of mobile devices' location data received from GPS sensors with special mobile interfaces in gathering road data for road disturbances.
\end{abstract}

\section{INTRODUCTION}

Because of the highway-weighted transportation in Turkey, frequent vehicle usage and heavy vehicles lead to damages in roads. Even if a new coating is applied to the roads, Figure 1 shows road disturbances can occur due to heavy vehicle usage. In addition, weather conditions also affect road disturbances. Particularly in the winter, there are disruptions, mainly cracks, in the regions where the freezing and thawing and high night and day temperature differences are high (Figure 2).

However, apart from these important factors that cause the road cover to deteriorate, faulty patches have been damaged on roads due to faulty manufacturing such as inadequate drainage, use of inappropriate filling materials and insufficient compaction (Movea, 2013). This situation poses a great threat both in terms of driving safety in our country where traffic accidents are experienced intensively, and it also significantly decreases road quality in terms of aesthetics (Movea, 2013). According to the KGM 2017 Traffic Accidents summary data (KGM, 2017) (Table 1.), "Loose Material on the Road" and "Individual Pit on the Road" are the main causes of causal road disturbance in mortal and injured traffic accidents. This study will explain the detection of road disturbances by the mobile device interface and the web interface using the GPS sensor of mobile devices to detect the road disturbances that occur on the roads.

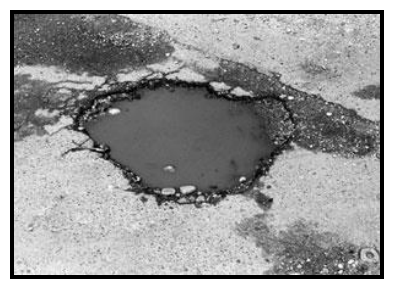

\begin{tabular}{|c|c|c|c|c|c|c|}
\hline \multirow{2}{*}{$\begin{array}{c}\text { ROAD } \\
\text { DEFECTS }\end{array}$} & \multicolumn{2}{|c|}{ Settlement } & \multicolumn{2}{|c|}{$\begin{array}{c}\text { Outside } \\
\text { Settlement }\end{array}$} & \multicolumn{2}{|c|}{ Total } \\
\hline & & $\%$ & & $\%$ & & $\%$ \\
\hline $\begin{array}{l}\text { Loose } \\
\text { Material } \\
\text { On the } \\
\text { Road }\end{array}$ & 181 & 37,01 & 361 & 69,83 & 542 & 53,88 \\
\hline $\begin{array}{c}\text { Individual } \\
\text { Pit on the } \\
\text { Road }\end{array}$ & 116 & 23,72 & 70 & 13,54 & 186 & 18,49 \\
\hline $\begin{array}{l}\text { Ribbon } \\
\text { Collapse }\end{array}$ & 96 & 19,63 & 26 & 5,03 & 122 & 12,13 \\
\hline $\begin{array}{c}\text { Partial or } \\
\text { Individual } \\
\text { Collapse }\end{array}$ & 41 & 8,38 & 28 & 5,42 & 69 & 6,86 \\
\hline $\begin{array}{c}\text { Seating on } \\
\text { Wheel } \\
\text { Track }\end{array}$ & 43 & 8,79 & 16 & 3,09 & 59 & 5,86 \\
\hline $\begin{array}{c}\text { Low } \\
\text { Banket }\end{array}$ & 12 & 2,45 & 16 & 3,09 & 28 & 2,78 \\
\hline Total & 489 & 100 & 517 & 100 & 1006 & 100 \\
\hline
\end{tabular}

Table 1. Information Regarding Cause Highways For Death And Injured Traffic Accidents - 2016

Figure 1. Hole Creation on the Road (Movea, 2013)

\footnotetext{
* Corresponding author
} 


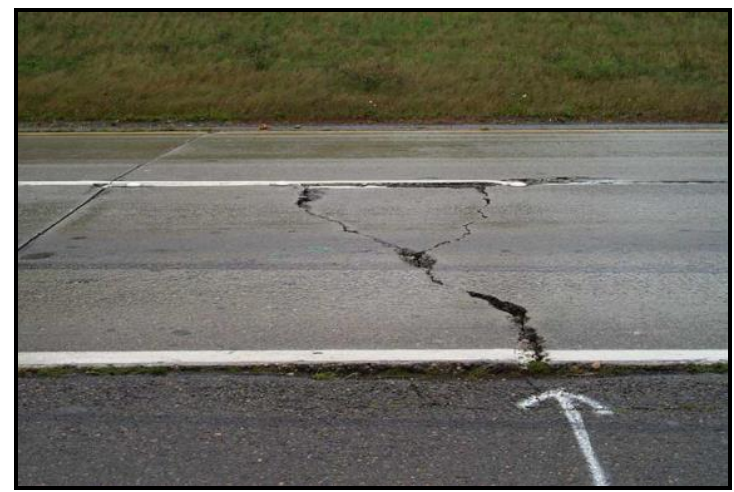

Figure 2. Crack formation on the road (Movea, 2013)

\section{MATERIALS AND METHODS}

\subsection{Materials}

Classical database management systems include attribute data such as the name of the road in which the disturbance is recorded, the number of kilometers in the road disturbance records. Not only attribute data and various graphics and statistics are sufficient. The use of attribute data in conjunction with spatial data allows a more understandable and analytical system. The most basic component of this proposed system is a spatial database management system in which spatial data are stored. The database management system used in the proposed system is PostgreSQL. The open source PostgreSQL also requires the PostGIS plugin to be installed to do spatial operations. QGIS, an open source geographic information system, is also used for analysis of spatial data. The spatial data stored in QGIS and PostgreSQL can be represented as a vector map layer. Spatial analysis can be done on this map layer. Detailed report and output can be obtained with different style definitions. With the increase in the number of mobile devices connected to the Internet, which is widely used today, it is also necessary for the work to be done to be easily shared with the institutions. The spatial data created for this should be shared online. It is possible to establish a map server for publishing and to publish the data via this server. The open source Geoserver map server can be used for posting on the web of the spatial data held in PostgreSQL. Direct PostgreSQL connection can be made with Geoserver and geographical data can be published to stakeholders and all persons over the web. It can also be provided on special displays using direct Geoserver WMS (Web Map Service) layers in web interfaces to be prepared. The WMS layers that are created can be used only by granting a link to the stakeholder person or institutions and defining the authorities.

\subsection{Methods}

\subsubsection{Highway Disturbance Data Creation with Mobile Interface:}

In road disturbances, saving road disturbance data in the in-situ is important to data accuracy. For in-situ data collection, the mobile device's GPS sensor is used to track the corrupted part of the road. In this way, if the parts of the road disturbance, only the thematic maps of those parts can be created, spatial and attribute data analysis can be done. Tablets or smartphones can be used for data collection. Tablet usage can provide easier and more detailed data collection. The GPS sensor of the mobile device needs to be used to obtain the data of the disturbances in the highways. While the GPS sensor is active, the field teams start the mobile interface from their mobile devices and start recording at the point where the road disturbance starts with their vehicles. Data recording can be in various forms.

The process of obtaining the road disturbance data of the teams in the field is explained in 4 steps. First of all, the field team is collecting the road disturbance data and matches the $x$ coordinates, y coordinates, start time and end time information with the road id data. With this step, spatial data will be collected. In the meantime, spatial location data is collected by NMEA (National Marine Electronics Association) protocol. The NMEA message format has been developed by the US National Marine Electronics Association for navigation in marine vehicles. Simply, yet all-inclusive data that is needed in navigation is widespread because it is an ascii-based data format. The NMEA protocol consists of a message sequence starting with the GP code and changing the information content with further additional encodings. The data sent by GPS has codes beginning with $\$$, followed by the starting code (Tiryakioğlu, 2014). The collected data in the NMEA format is used not only for road disturbance detection but also for additional information provided outside the location and for storing the live data which can be used when necessary. At the interface on the mobile device, the location information can be defined at which time interval or how much distance the data is exchanged. Field teams may position periodically at 10 seconds from the starting point, as well as options such as position taking when 5 meters are displaced. The GPS data received from the satellites in step 1 is recorded on the mobile device of the field team in the vehicle.

In the second step, the road disturbance data are obtained by completing the process related to the faulty part of the road. The collected NMEA data (Figure 3 ) are filtered at this step as $\mathrm{x}$ and $y$ coordinates. NMEA data is obtained and data conversion is provided at the same time as the data collection process of road disturbance is continued. The field team collects coordinate data from the starting point to the point where it finishes. When the process finishes (Figure 4), the road disturbance spatial data is stored in the form of an $\mathrm{xml}$ file (Figure 5) on the mobile device. The finished road disturbance is shown as a line object on the screen of the mobile device, whichever coordinates are taken at the end of the disturbance detection process (Figure 6).

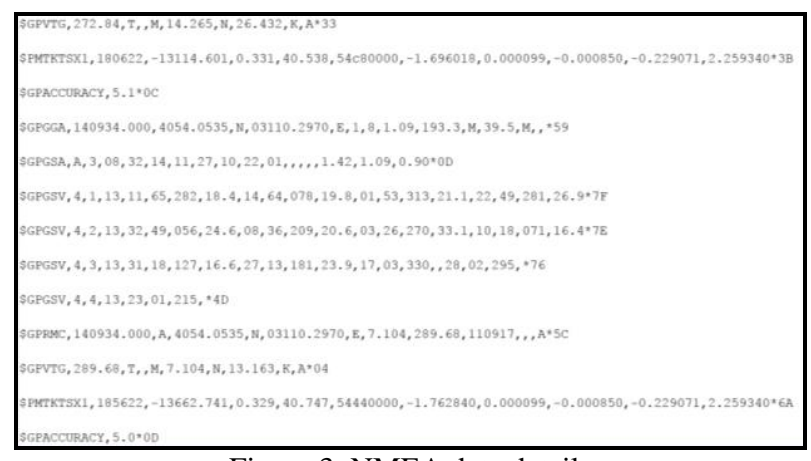

Figure 3. NMEA data details 


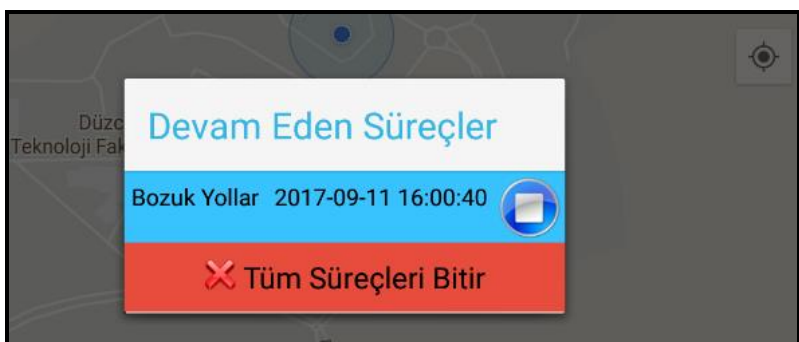

Figure 4. Displaying continuing processes of road disturbance detection

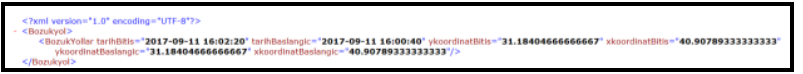

Figure 5. Obtain road disturbance data from conversion of NMEA data in XML format

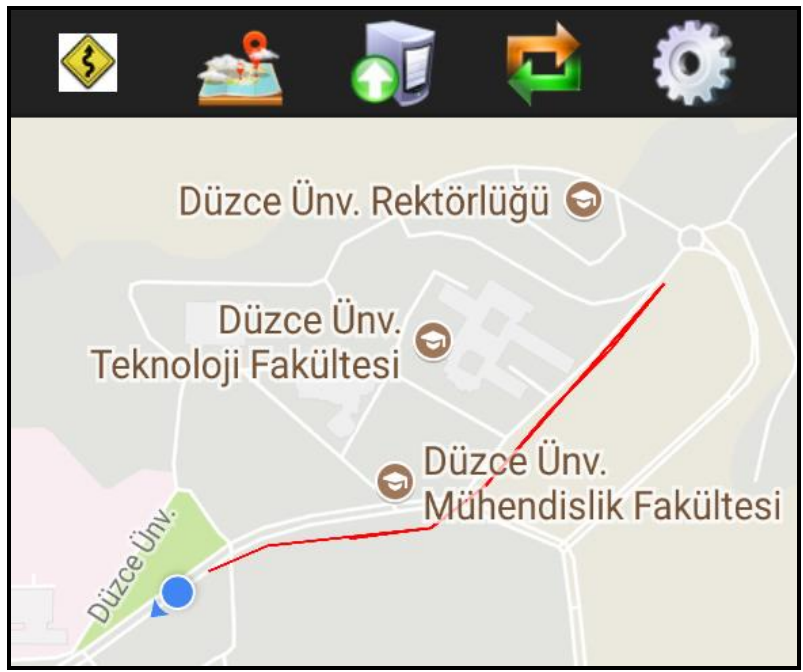

Figure 6. Displaying field team's route to obtain road disturbance data

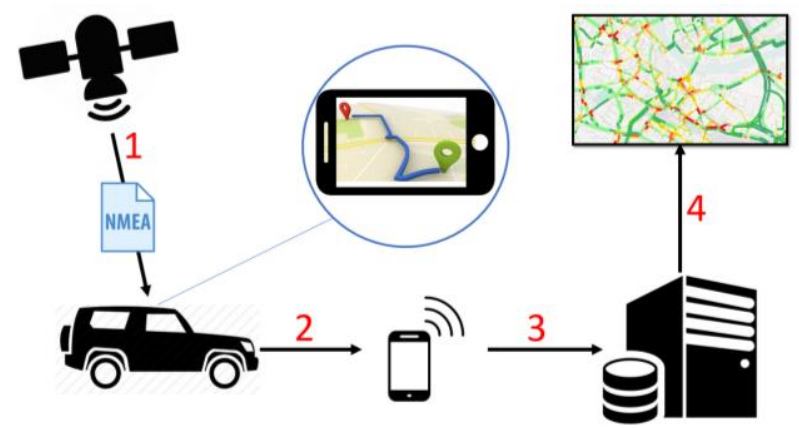

Figure 7. Steps of obtain road disturbance data

In the third step, the road disturbance data stored in xml format on the mobile device is sent to the server via internet. The server processes the received $\mathrm{xml}$ data with using the prepared web service and transfers it to the PostgreSQL database management system. The task of the field teams is finished after collecting and sending out roadside data.

In the fourth step, the data transferred to the PostgreSQL database management system is processed spatially via PostGIS. Along with this step, the road disturbance data can be displayed as attribute data in the web interface. Current status can be displayed instantly with graphical representations. Also the spatial data can be viewed and shared as a thematic map with Geoserver web server as appropriate. Figure 7 shows all of these 4 steps with relations.

\subsubsection{Highway Disturbance Data Creation with Web Interface:}

The digital road data provided through the database management system is displayed as both attribute and spatial in the web interface. As the attribute data, the control segment number, district, grade, individual status, definition and explanation information of the group are displayed. And spatial data is on the PostgreSQL database management system. The highway selected by the person using the web interface displays the data as geographical data on the map screen. After the roads are kept on the database management system, the road is selected from the list according to the road disturbance complaint and the complaint record is defined from the road disturbance data adding screen.

The authorized person adds to the system the way in which the meter is disturbed (e.g. the selected highway is between 1000 and 1500 meters). With this definition, when the system is being recorded, the roads with the highway information together with the selected highway information are sent to the PostgreSQL database management system as parameters. Through the PostGIS plug-in, the part of the highway between the specified meters is copied to the road disturbance table as a separate geographical object. Figure 8, lists all roads in the road network. The control segment number, district, grade, group individual status, description and description attribute information for the route are shown.

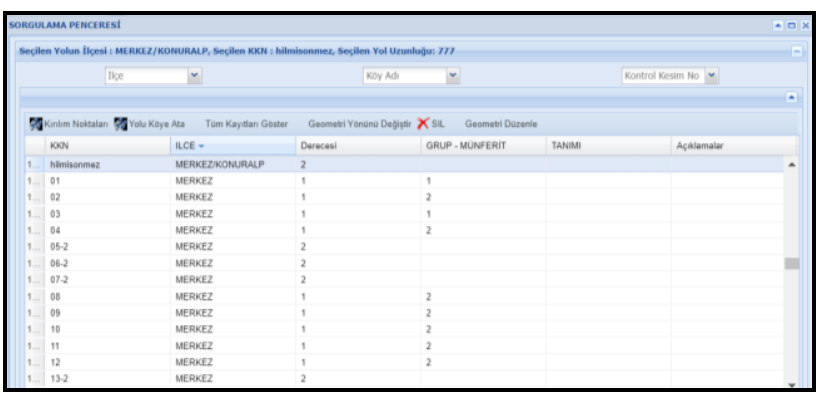

Figure 8. Listing all highway records

In Figure 9, the selected route from the list is shown on the map. The map is displayed on the map using the spatial data of the highway held in PostgreSQL.

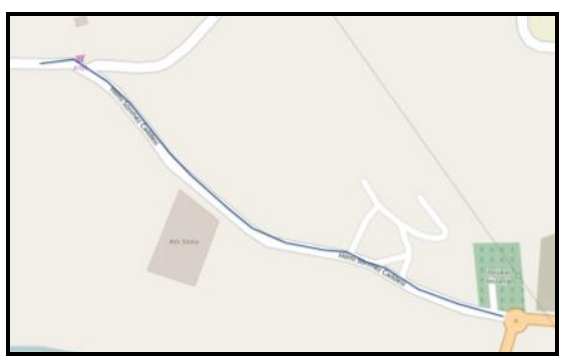

Figure 9. Spatial representation of the selected highway on the map

Figure 10 shows the web interface to which the disturbance data can be added on the selected highway. It is possible to define multiple road disturbances in the range of road lengths, which is the starting point on the road is 0 meters to the ending point. 
Deletion can be done for the disturbances. In Figure 10, 4 road disturbances are defined for the selected road.

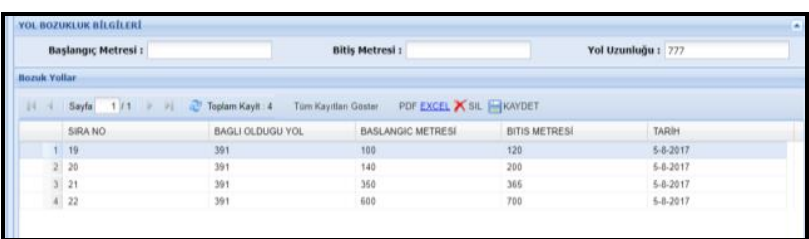

Figure 10. Addition of disturbances on the selected route to the system

In Figure 11, 4 road disturbance data added to the selected road are shown. Apart from the selected road disturbance data, all the disturbances in the road network can also be displayed on the map and the general road situation of the province can be displayed at once. Thus, the competent authority can instantly display in which regions the roads in the highway network visually concentrate where they are. In addition, the in-house performance evaluation can be performed by displaying the remedied roads as a separate layer.

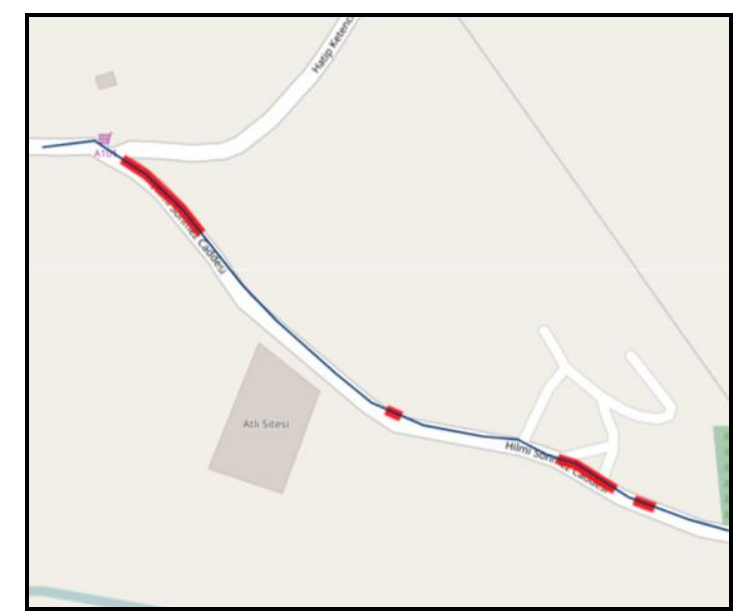

Figure 11. Display of added highway disturbance data on the map

In Figure 12, a measurement of the defined data is made by the measuring tool in the web interface. Related record is 100 meters. The approximate actual value was obtained when measurements were made manually on the map.

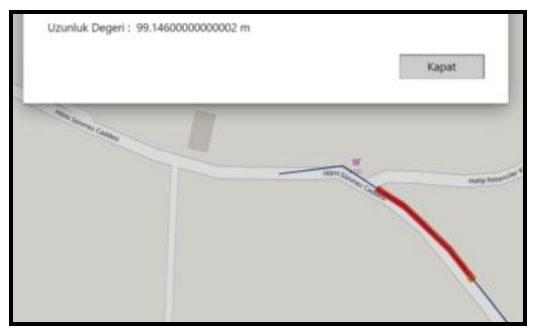

Figure 12. Approximate measurement of road disturbance record by measurement tool

In the "Geom" column a copy of the selected highway was taken according to the start and end meter values specified in the web interface. In the database, it is stored as spatial data. The data in the other columns are stored as attribute. In order to create the segment road disturbance data in the "Geom" column, the length of the selected highway was first determined by the SQL query Figure 13.

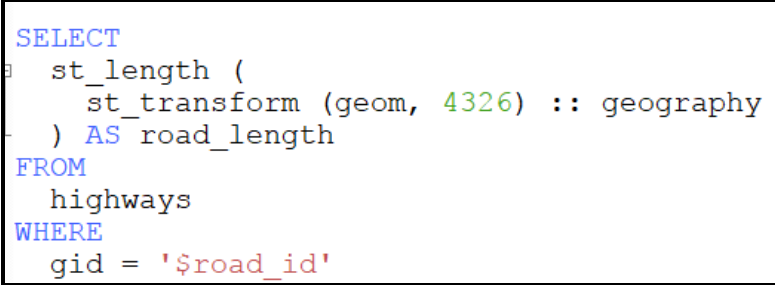

Figure 13. Getting length of selected road with PostGIS Spatial Function

st_transform (geom, 4326) : : geography

Figure 14. Geometry transforming with PostGIS spatial functions

Using the PostGIS functions, the geographical data is converted to the EPSG: 4326 coordinate system to obtain the length in meters by the definition made in Figure 14 the length of the converted geographical data in meters is obtained with the st_length () function. After the length is obtained, the SQL query is used for the parts of the highway that are corrupted with the ST_line_substring function (Figure 15), geographic data is segmented and transferred to the database management system (Figure 16).

select ST_Line_substring (geom, \$start, \$finish)

Figure 15. Segmenting geometry data with PostGIS functions

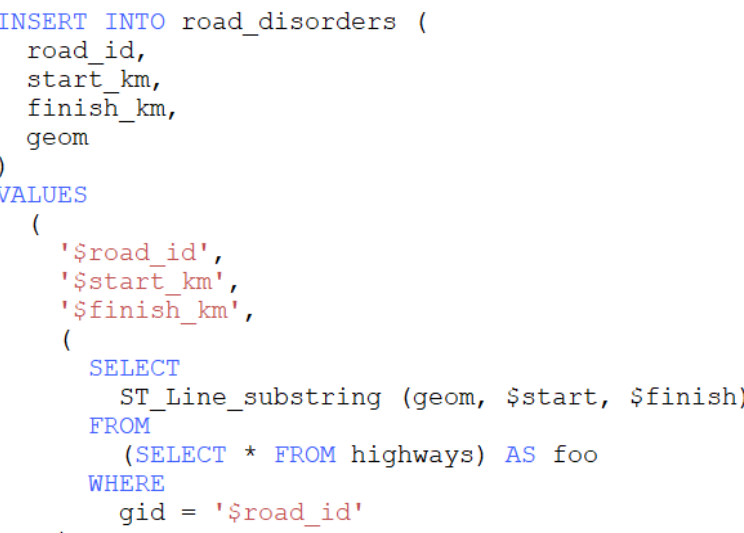

Figure 16. Adding segmented geometry data to database management system

After adding data to database management system, spatial data is displayed as in Figure 17.

\begin{tabular}{|c|c|}
\hline gid & 22 \\
\hline anaobjeid & 391 \\
\hline altobjeid & \\
\hline kmbitis & 700 \\
\hline yapimyili & 5-8-2017 \\
\hline kmbaslangic & 600 \\
\hline geom & $010500002031 \mathrm{BF} 0 \mathrm{D} 00010000000102000000040000003011$ \\
\hline
\end{tabular}

Figure 17. Representation of attribute and spatial data of a sample road disturbance record 


\subsubsection{Data Analysis}

In the analysis phase, current and past road disturbance data can be displayed graphically on the fly. In-house performance evaluation can be done according to the start and end date of the complaint. The current stock status can be checked according to the amount of materials used.

\section{RESULTS AND RECOMMENDATIONS}

It is fast and low cost with the use of open source geographic information systems in the detection of road disturbance. Analysis of the provincial general can be made by storing the disturbance data in the database in a spatial manner. With the rapid detection and elimination of road disturbances, it is possible to avoid possible loss of material and life. In our future work, we will consider to use mobile device's accelerometer and gyroscope sensors for disturbance detection, so there will be no need for human intervention.

\section{REFERENCES}

Movea, 2013. http://www.movea.com.tr/asfalt-bozulmalarineden-olusur (15 Jul 2017)

KGM Trafik Güvenliği Dairesi Başkanlığı, 2017. Trafik Kazaları Özeti 2016.

http://www.kgm.gov.tr/SiteCollectionDocuments/KGMdocume nts/Trafik/TrafikKazalariOzeti2017.pdf (05 Aug 2017)

Tiryakioğlu, 2014, http://ibrahimtiryakioglu.com/dersler/ozelolcmeler/rtk_veri_formati_ders3.pdf (10 Sep 2017) 